\title{
Applying Functional Analysis to Study the Airline Pilot's Perspective on Human- Human I nteractions during Flight Operation
}

\author{
Matthias Groppe ${ }^{1, a,{ }^{*}}$, Marc Bui ${ }^{2, b}$ and Romano Pagliari ${ }^{1, c}$ \\ ${ }^{1}$ School of Engineering, Cranfield University, Bedfordshire, MK43 OAL, UK \\ ${ }^{2}$ The Laboratoire d'Informatique et des Systèmes Complexes, EPHE Sorbonne, 52 Rue Gay \\ Lussac, 75005 Paris France
}

\begin{abstract}
The objective of the study is to understand the cooperation building process within HumanHuman Interaction (HHI) during Collaborative Decision Making (CDM) in a distributed, multipleobjective decision making environment. It is based upon functional HHI analysis within typical CDM flight operation situations where the flight operation includes the inbound, turn-round, and outbound phases of the flight. A survey was undertaken which sought to identify aircraft pilots' perspective on cooperation with other operators during various flight situations. In this study, different situations are compared and characterized by: (1) a synchronous interaction mode, where all participating operators interact with each other at the same time, and (2) an asynchronous interaction mode, where the participating operators interact with each other at different times. Task and decision-making for all situations is distributed between operators. The aircraft pilot's perspective and their information requirements during these flight situations are used to identify critical information processing during CDM.
\end{abstract}

KEYWORDS: Air traffic management, asynchronous distributed collaboration, collaborative decision making, cooperation, human-human interaction

\footnotetext{
a Matthias Groppe is a doctoral researcher at EUROCONTROL Experimental Center in Brétigny sur Orge. He earned his master's degree in Business Administration at the City University of London. The PhD research project is supported by FRAPORT foundation and EUROCONTROL. Matthias Groppe is employed as a pilot and flight instructor at Lufthansa CityLine.

* Corresponding author. E-mail: m.groppe@cranfield.ac.uk, phone: +49 (0)178 2862642

${ }^{b}$ Marc Mui is Professor and Directeur d'Etudes cumulant at Ecole Pratique des Hautes Etudes of the Sorbonne Paris. $\mathrm{He}$ is also the Head of the Laboratory of Complex Systems at Ecole Pratique des Hautes Etudes and Professor at University of Paris 8. His research interest is Prétopologie and the Behaviour of Complex Systems.

${ }^{\mathrm{c}}$ Romano Pagliari obtained a masters degree in transport and a $\mathrm{PhD}$ in airport slot allocation from the Cranfield University School of Management. His research interests include airport management and air transport issues that affect remoter regions. Romano is currently Director of the MSc in Airport Planning and Management, a member of the Scientific Committee of the International Center for Competitiveness Studies in Aviation and a member of the editorial board of the Journal of Airport Management.
} 


\section{I NTRODUCTION}

Updated from earlier projects in the United States, the European CDM approach was introduced during field trials at selected European airports with the aim of achieving cooperation at planning leve/via information sharing and common situational awareness (CSA). However, from aircraft pilots' perspective on current air traffic operation, many problems encountered with CDM arise from human-human interactions ( $\mathrm{HHI}$ ) at action level; whereby $\mathrm{HHI}$ at action level refers to interactions with a shorter time span and less abstraction than $\mathrm{HHI}$ at planning level (Hoc, 2000). Further problems for CDM operation are conditioned on the specific situation of decision-making in an asynchronous, distributed collaboration environment as can be found in ATM operational decision-making. Operators, like aircraft pilots, ground handlers etc, communicate with the operational centres of the airlines, ATC, and the airport through speech (e.g. via phone or radio) or written text (e.g. via ACARS). This paper will seek to understand how the airport CDM information-sharing process is influenced by the following variables:

- Interaction Mode (synchronous versus asynchronous)

- Information Distribution (homogeneous versus heterogeneous)

Even little understanding of how operators think during CDM exists (Terveeen, 1995), an analysis of $\mathrm{HHI}$ within CDM via the perspective of a single operator (aircraft pilots) is used in order to cope with the still very inadequate mechanisms of collaborative problem-solving during operators' decision-making. According to Ferber (Ferber, 1995), HHI situations can be classified as antagonistic, cooperative, or indifferent depending on the aims, resources, and abilities, held by each participating operator. This classification is applied in order to understand micro-level cognitive aspects of $\mathrm{HHI}$ in CDM flight operation situations. The advantage of using aircraft pilots as a reference group is that they are not penalised for failing to meet punctuality targets. The existing method of delay assignment seeks to identify the cause of delay and assign the responsibility to a single operator via defined delay codes. Usually each operator tries to avoid assignment of a delay due to the penalties than can be expected.

In this paper, prototypical HHI situations between all operators involved in flight and turn-round operation are introduced. They all take place in a distributed collaboration environment, where coordination of processes is necessary. Processes include parking, ramp-side, land-side, and special ground handling processes. Within these situations, cooperative HHIs are mandatory: pilots have to coordinate processes with other operators like representatives of the ground 
handling companies, airport, airline, air traffic control, and Central Flow Management Unit. Cooperation and decision-making is distributed between pilots and other operators. Decisionmaking at the start of the turn-round process is designed to facilitate the processing of the aircraft (e.g. boarding, de-boarding, refuelling, cleaning..) - this is the responsibility of pilots. Other operators will make decisions in order to coordinate and execute various processes designed to achieve a successful and punctual turnaround. These operators will often need to cooperate with each other. While any delayed process start can result in an overall delay of the subsequent flight, coordination of a standard turn-round (defined as a reference model) is usually predetermined.

During a normal turn-round operation, interactions between pilots and other operators can be synchronous or asynchronous. Coordination of actions takes place via predetermined key events (milestones), organized as a sequence of interactions between operators within the airport operations centre; if a non-standard situation like aircraft change, technical repair, adverse weather operation, etc. occurs, ad hoc coordination of all necessary events via face-toface communication between pilots and ramp agents or via radio/ phone between pilots and other operators coordinating from airport operation centre takes place. The milestone approach used for CDM, includes all events which are necessary for an uninterrupted turn-round process, whereby some key events take place already far ahead of the turn-round itself. Information distribution during turn-round is mainly heterogeneous between participating operators on action and planning level caused by the information dynamics in the highly dynamic environment of the turn-round operation and the varying tasks in the different domains themselves. However, in order to cope with the usually limited time span for turn-round operation, CDM targets homogeneous information processing achieved through a CSA between all participating operators and to avoid departure delay caused by non-standard operation.

Other proposed situations concern the inbound or outbound phases of the flight, starting from aircraft leaving the parking position until reaching parking position at the destination. Coordination here is also necessary for departure and arrival sequencing with other aircraft, usage of taxiways, airways and airspace/ sectors. It is the pilot's responsibility to execute the flight according defined rules under consideration of highest degree of safety possible. The other operator involved for coordination of traffic during flight is air traffic control (ATC). ATC seek to ensure that there are safe separation distances between aircraft and they manage air 
traffic flow by issuing clearances to pilots. The different level of control between pilots and other operators like ATC in this situation is that ATC has authority about assigning the airspace in the form of clearances to the pilots and again this depends on the cooperation of pilots in adhering to these clearances. Decision-making is shared between pilots and ATC within their domains relative to the situational need, but has to be executed under previously-mentioned safety constraints. Other operators like the Airline Company or Central Flow Management Unit (CFMU) are only marginally involved in decision-making during the flight operation phase.

During the inbound phase of the flight, interactions between pilots and air traffic control are synchronous established via radio communication; however interactions between air traffic controllers of different sectors can also be asynchronous, resulting in a non-coordinated flight through different sectors. Interactions between pilots and other operators are usually asynchronous and distributed. Information interactions for the issue of clearances concerning airspace and routing are always homogeneous, while information distribution for reasons of the deviations from previous clearances can be homogeneous or heterogeneous.

During the turn-round phase of a flight, the complexities of the operation result in high dynamic information content. While some information like variations in flight progress occur on a standard basis and changes are automatically accessible to all participating operators via data link transmission, non-standard information like operational changes or technical issues, are transferred by non-synchronized interactions and need to be manually transmitted between operators. This requires cooperation among operators' interactions and defines the need to achieve a common situational awareness among all operators.

The resulting objectives for this paper study are:

- To understand the cooperation building processes of the HHI during day-to-day flight operation which are necessary in the context of a distributed collaborative decisionmaking environment across objective functions of all operators.

- To identify the information sharing components which should be employed to optimize the CDM concept in ATM typical standard \& non-standard flight situations.

- To understand how agents can support humans in achieving collaborative knowledge during distributed collaborative problem-solving. 


\section{THEORETICAL BACKGROUND}

In our context of flight operation, HHI are seen as dynamic relations between pilots and other operators via a number of mutual actions. Each action by one operator has consequences which influence the behaviour of others. A series of actions form events and a number of events form the turn-round or flight situation (e.g. ATC assigns a parking position for the aircraft to the pilots (event) via mutual communication usually by two-way radio communication (HHI) in a turn-round situation). Ferber (1995) defines interaction situations as a number of behavioural patterns which evolves from a group of agents, who have to act in order to reach their targets and thereby have to regard their more or less limited resources and capabilities. By using this definition, interaction situations can be described and analysed, because it defines abstract categories like cooperation, antagonism, and indifference via differentiation of observed key commonalities and different interaction situations. The relevant components for classification of interaction situations are the aims and intentions of the different agents, the relations of the agents to available resources, and abilities of the agents in regard to their assigned task. These criteria are used to define different types of interaction situations as shown in Table 1.

Each type of interaction situation has its own category. In an Independence situation, no interaction takes place and sufficient resources and abilities allow a coexistence of operators without any constraint. This situation has no relevance for ATM at congested airports. A Simple Working Together situation defines a collaboration situation which does not require coordination between operators, while a Blockade, Coordinated Collaboration, Pure Individual/Collective Competition and Individual/Collective Resource Conflict are situations which are expected to dominate in our contemplated HHI situations. These situations require coordination between operators and, depending on resources, aims, and abilities, can result in cooperative or antagonistic behaviour.

During flight operation situations, $\mathrm{HHI}$ are usually not binding relations between involved actors and no mutual influence is exercised between pilots and other operators; therefore social components of the interactions are not contemplated. According Hoc (Hoc, 1998, 2001), cooperation can exist within various levels in terms of distance from the action itself: A cognitive architecture of cooperation model classifies cooperation in abstraction level and process time depending on the proximity to the action itself is shown in Figure 1. 
Table 1 - Classification of interaction situations

\begin{tabular}{|l|l|l|l|l|}
\hline Aims/ Interests & Ressources & Abilities & Type of Situation & Category \\
\hline compatible & sufficient & sufficient & Independence & Indifference \\
\hline compatible & sufficient & insufficient & Simple working together & Indifference \\
\hline compatible & insufficient & sufficient & Blockade & Cooperation \\
\hline compatible & insufficient & insufficient & Coordinated collaboration & Cooperation \\
\hline incompatible & sufficient & sufficient & Pure individual competition & Cooperation \\
\hline incompatible & sufficient & insufficient & Pure individual competition & Antagonism \\
\hline incompatible & insufficient & sufficient & Individual resource conflict & Antagonism \\
\hline incompatible & insufficient & insufficient & Collective resource conflict & Antagonism \\
\hline
\end{tabular}

Source: Ferber (1995)

For the study of HHI situations, the focus is on cooperation (or antagonism, if relevant) at action level. At action level, the operators perform operational activities related to their individual goals, resources, and abilities. Hoc (Hoc et al., 1998) has defined four types of activities at action execution level which are interference creation (e.g. mutual control), interference detection, interference resolution, and goal identification (goal identification also embodies identification of other operators goals). Cooperation at action level has short-term implications for the activity, as opposed to the more abstract type of cooperation at planning level. Interference creation relates to the deliberate creation of interactions; interference detection to the ability of detecting interferences, especially in non-deliberate interference situations; and interference resolution to the actual interaction in order to find a cooperative solution. Mutual domain knowledge is the basis for other operators' goal identification, to facilitate operator's own task, the other's task, or the common task.

At planning level, operators work to understand the situation by generating schematic representations that are organized hierarchically and used as an activity guide (Hoc, 1998). Schematic representations include the concept of situation awareness (Salas et al., 1995), and operators' goals, plans, and meta-knowledge (Hoc, 1998); therefore the current approach to CDM operation in ATM is seen as an approach towards cooperation at planning level. De 
Terssac and Chabaud (1990) use the term COFOR (Common frame of Reference) as a mental structure playing a functional role in cooperation and as a shared representation of the situation between operators likely to improve their mutual understanding (Carlier et al., 2002). The top most level in Hoc's model, the meta-cooperation, is level developed from knowledge of the other two levels. This dimension is not contemplated in the study.

Figure 1 - Processing architecture of cooperation

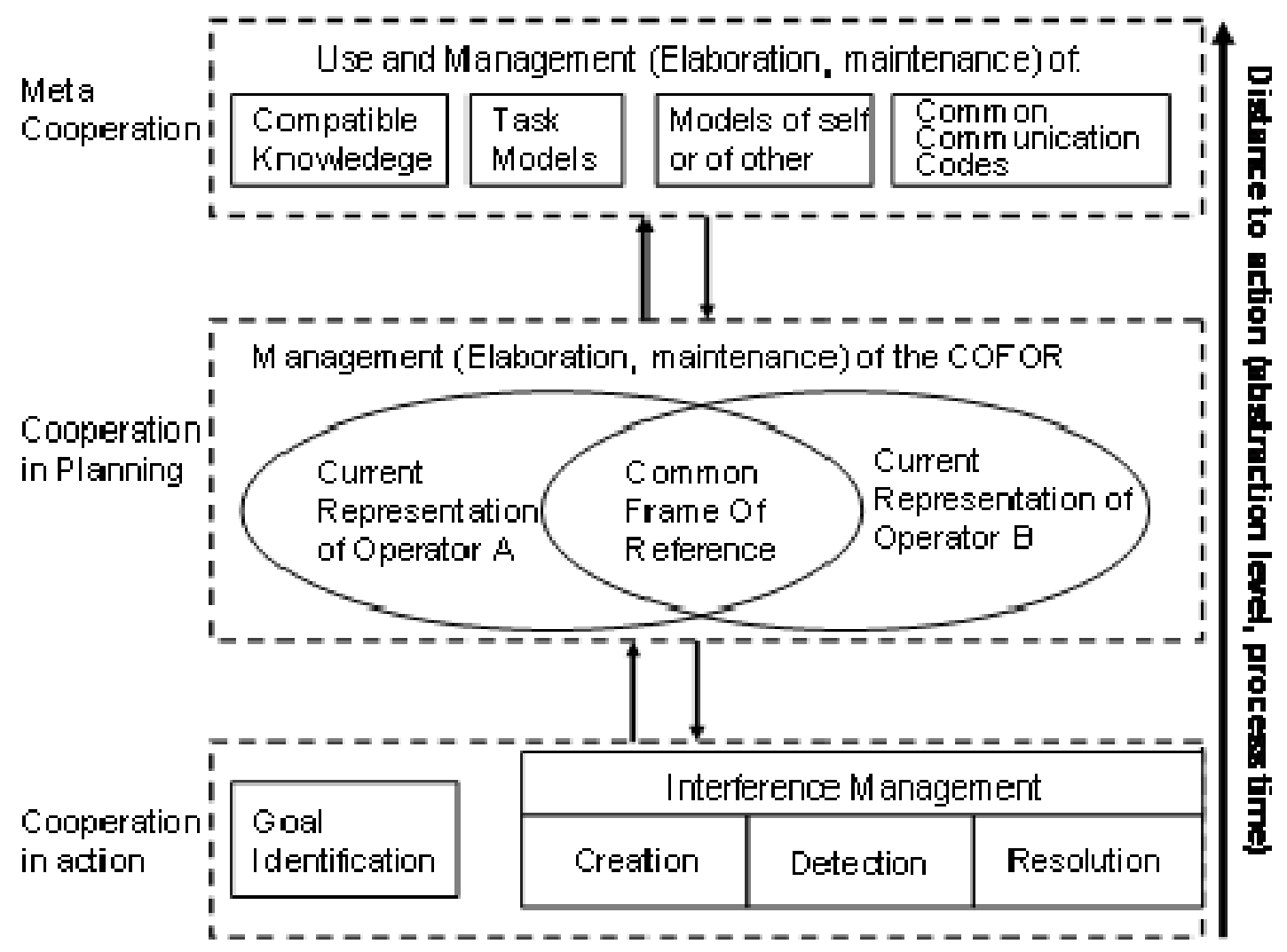

Source: Hoc (2000)

Piaget (1965) distinguishes between cooperation seen from structural (e.g. network organization) or functional perspectives which covers cooperation as activities performed by individuals within a team in real time. Two minimal conditions must be met in cooperative situations: (1) each actor strives towards goals and can interfere with other actors on goals, resources, and procedures. (2) Each actor tries to manage interference to facilitate individual activities or a common task. Both conditions are not necessarily symmetric, because goal orientation or interference management depend on individual behaviour or time constraints. 
Hoc (2001) argues that current air traffic management (ATM) is more concerned with operators' plans, goals, or role allocation instead of common situational awareness. But Lee (2005) lists situational awareness, responsibilities and control, time, workload, and safety constraints as key factors driving collaborative behaviour in air traffic control operations. To have proper awareness of the situation, a controller and/or pilot needs to initiate or be informed of actions taken by other operators. However, time pressures brought on by the need to meet various operational and safety-related targets will have an adverse effect on communication, cooperation and the extent of common situational awareness.

Share of responsibility and control are often different but determined through situation (e.g. air traffic controllers issue clearances which have to be executed by pilots). Nevertheless, the more assistance, the more anticipative the mode of operation in controllers and the easier the human-human cooperation (Hoc, 1998). Collaborative Decision Making means applying principles of individual decision making on groups, whereby groups are established with the aim to show collectively a specific behaviour (Jennings et al., 2001). This implies that cooperation of participating individuals should be beneficial for CDM operation, also in air transport management. But how does cooperative work look like on day-to-day basis? Cooperation has a wide variety of connotations in everyday usage (Schmidt 1994). Do people only cooperate, if they are mutually dependant in their work or is mutual dependency sufficient for cooperation to emerge? In the context of CDM operation, confrontation and the combination of different perspectives of cooperation is an issue: how is the pilot's perspective embedded in the current CDM approach? For Schmidt (1994), the multifarious nature of the task can be matched by application of multiple perspectives on a given problem via articulation of the perspectives and transforming / translating information of different domains.

The challenge of CDM operation in ATM is the unique cognitive mechanisms in a distributed and highly dynamic environment as can be found in flight operations. Similar situations can be found in military teams with asynchronous, distributed teams for mission planning and mission execution, but in general it is a relatively new area (Keisler et al., 2002). Other domains which have related aspects to asynchronous distributed collaboration are not contemplated. Warner (Warner et al., 2002, 2003) describes the major factors impacting collaboration which are the collaborative problem environment, operational tasks, collaborative situation parameters, and team types (Table 2). 
His structural model of collaboration focuses on team decision-making, course of action selection, developing shared understanding, and intelligence analysis. Thereby, various parameters can influence the collaboration performance (Warner et al., 2006). The collaborative decision parameters can be adapted to fit the specific environment of CDM in other domains using the respective characteristics under operational tasks, collaborative situation parameters, and team types. Werner's structural model of team collaboration uses the minimum number of unique stages identified in team collaboration literature and the results from a collaboration and knowledge management workshop (Figure 2).

Table 2 - Problem area characteristics for collaboration

\begin{tabular}{|c|c|}
\hline Collaborative Situation Parameters & Team Types \\
\hline $\begin{array}{ll}\text { - } & \text { Time pressure } \\
\text { - } & \text { Information/knowledge } \\
\text { - } & \text { Time pressure } \\
\text { - } & \text { Information/ knowledge } \\
\text { - } & \text { Uncertainty } \\
\text { - } & \text { Dynamic information } \\
\text { - } & \text { Cognitive overload } \\
\text { - } & \text { Complexity } \\
\text { - } & \text { Human agent }\end{array}$ & $\begin{array}{ll}\text { - } & \text { Asynchronous } \\
\text { - } & \text { Distributed } \\
\text { - } & \text { Culturally diverse } \\
\text { - } & \text { Heterogeneous knowledge } \\
\text { - } & \text { Unique roles } \\
\text { - } & \text { Command }\end{array}$ \\
\hline
\end{tabular}

Source: Warner (2003)

Figure $\mathbf{2}$ - Structural model of team collaboration

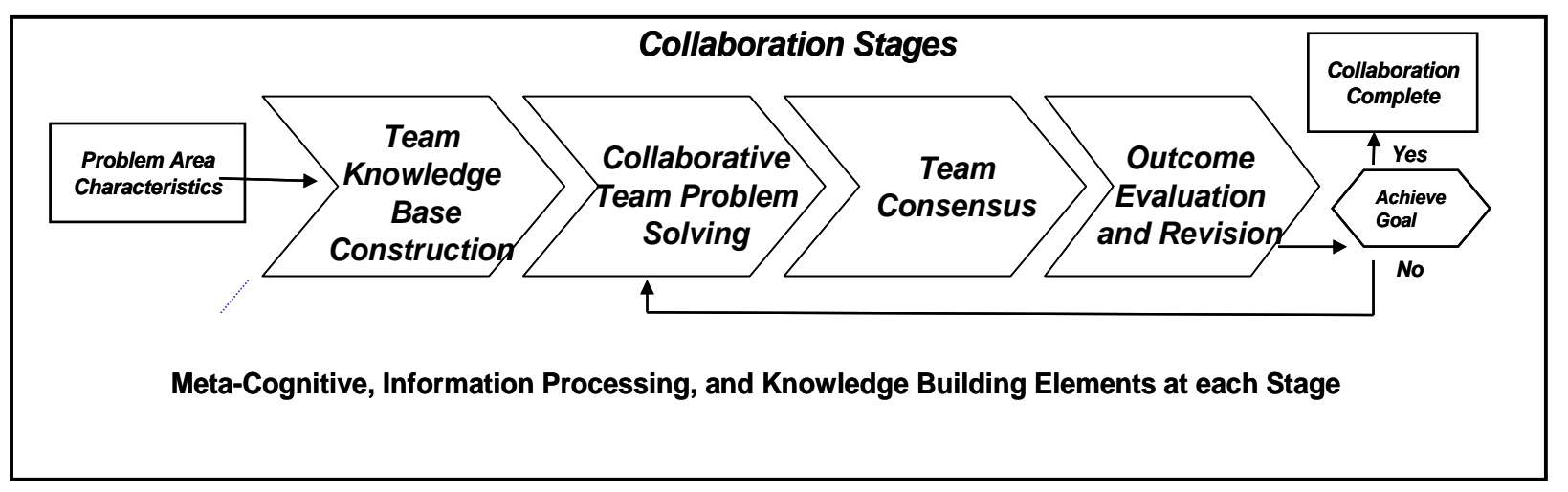

Source: Warner (2003) 
This structural model is based on the meta-cognitive processes of an information processing and communication approach. For Davidsen (Schmidt, 1994), meta-cognition is the knowledge of one's own cognitive processes in explaining how human cognitive processes are used for problem solving. According Werner, there is 'no generally recognized unified theory of human cognition'. By implementing Ferber's component approach, a micro level cooperation perspective is applied into the structural collaboration model. This approach allows adapting the structural model of team collaboration to a distributed decision-making environment under consideration of decision-making across objective functions (e.g. like Airport CDM).

\section{METHODOLOGY}

A methodological approach is used for the analysis of the cooperative mechanisms within HHI. First, all flight \& turn-round situations which are seen as critical for CDM operation in terms of punctuality are determined via in-depth interviews with senior commanders of different airlines. All situations were decomposed into elementary activities and thereafter grouped into event classes. The classes within turn-round situations include the subclasses gate assignment, standard ramp services, standard land-side services, and non-standard turn-round services. Some event classes have only one possible event as problem cause.

For each event class, the collaboration stages analogous Werner's structural model were identified. To understand how participating operators think during each stage, a selfadministered questionnaire was developed which aims at getting knowledge about information processing (meta-cognitive level) and interaction components (micro-cognitive level) between participating CDM operators within distributed collaborative decision-making. All questions were designed from the perspective of the airline pilots as members of distributed airport collaborative decision making (perspectives of other operators could also usefully be researched). As reported by airline pilots, all event classes have critical elements concerning collaboration. Therefore, the questions are designed to find the most problematic stage within the collaboration process. 


\section{DEMONSTRATION}

\section{Critical Human-Human Interactions}

30 pilots from different airlines were asked during unstructured questioning to name processes with problems in regard to $\mathrm{HHI}$ during day-to-day flight and turn-round operation. From all mentioned examples, five critical situations were defined and Table 3 provides an overview of the situations as reported by the airline pilots.

Table 3 - Critical information sharing situations

\begin{tabular}{|l|l|l|l|l|}
\hline \multicolumn{1}{|c|}{ TURN-ROUND } & COOPERATION & $\begin{array}{l}\text { COOPERATIVE } \\
\text { COMPONENT }\end{array}$ & FREQUENCY & RELEVANCE \\
\hline Parking Stand Availability & $\mathrm{Y} / \mathrm{N}$ & $\begin{array}{l}\text { Aims/Resources/ } \\
\text { Abilities }\end{array}$ & $\begin{array}{l}\text { Daily/Weekly } \\
\text { /Monthly }\end{array}$ & $\begin{array}{l}\text { Delay Avoidable } \\
\text { Yes/No }\end{array}$ \\
\hline $\begin{array}{l}\text { Operational Information } \\
\text { to Cockpit }\end{array}$ & $\mathrm{Y} / \mathrm{N}$ & $\begin{array}{l}\text { Aims/Resources/ } \\
\text { Abilities }\end{array}$ & $\begin{array}{l}\text { Daily/Weekly } \\
\text { /Monthly }\end{array}$ & $\begin{array}{l}\text { Delay Avoidable } \\
\text { Yes/No }\end{array}$ \\
\hline $\begin{array}{l}\text { Operational Information } \\
\text { from Cockpit }\end{array}$ & $\mathrm{Y} / \mathrm{N}$ & $\begin{array}{l}\text { Aims/Resources/ } \\
\text { Abilities }\end{array}$ & $\begin{array}{l}\text { Daily/Weekly } \\
\text { /Monthly }\end{array}$ & $\begin{array}{l}\text { Delay Avoidable } \\
\text { Yes/No }\end{array}$ \\
\hline $\begin{array}{l}\text { ATC Information } \\
\text { Provision }\end{array}$ & & $\begin{array}{l}\text { Aims/ } \\
\text { Resources/ } \\
\text { Abilities }\end{array}$ & $\begin{array}{l}\text { Daily/Weekly } \\
\text { /Monthly }\end{array}$ & $\begin{array}{l}\text { Delay Avoidable } \\
\text { Yes/No }\end{array}$ \\
\hline $\begin{array}{l}\text { Ramp/Terminal Service } \\
\text { Problem }\end{array}$ & $\mathrm{Y} / \mathrm{N}$ & $\begin{array}{l}\text { Aims/ } \\
\text { Resources/ } \\
\text { Abilities }\end{array}$ & $\begin{array}{l}\text { Daily/Weekly } \\
\text { /Monthly }\end{array}$ & $\begin{array}{l}\text { Delay Avoidable } \\
\text { Yes/No }\end{array}$ \\
\hline
\end{tabular}

Source: Own Data (2007)

The underlying situations do not have any statistical relevance in terms of importance or frequency; the aim was to find a wide spectrum of possibly critical HHI. In particular, the identified critical situations at turn-round are:

- After landing, parking stand is still occupied

- During turn-round, delay of rampside ground handling process, e.g. baggage loading, catering, cleaning

- During turn-round, delay of landside (inside the terminal) ground handling process, i.e. check-in, security, boarding

- During turn-round, delay of special (non standard) ground handling process, i.e. wheelchair boarding, aircraft change

- During turn-round, departure delay or runway change from ATC because of high traffic density 
- During turn-round, missing information about operational changes at destination

- During turn-round, pilot's proposal of operational changes which were not considered as proposed

For each situation, pilots were asked to rate the cooperative behaviour of other operators:

- How or when information is given by other operators

- How much delay resulted from non-cooperative behaviour

- How important is information sharing for pilots in relation to the critical situation

- Which interaction component could be the reason for non-cooperation, if relevant: aims, resources, or abilities

- Would delay be avoidable with better information sharing, if relevant

\section{Questionnaire administration \& airlines involved}

The survey entailed cockpit crews from a range of airlines that had agreed to to participate. The questionnaire was administered on-line at the EUROCONTROL Experimental Centre server. All cockpit crew members were addressed directly by mail and additionally by face-to-face questioning. The questionnaire was available in the English and German languages.

\section{RESULTS}

\section{Pilots' General I nformation}

196 pilots participated in the survey representing Austrian Airlines $(n=2)$, Air Berlin $(n=16)$, Air France $(n=9)$, Austrian $(n=2)$, Easy Jet $(n=1)$, Lufthansa $(n=77)$, and Transavia $(n=1)$. Captains made up $44.6 \%$ of the sample with the remaining $55.4 \%$ consisting of first officers. The survey was accessible via internet for a period of three months. The number of participating pilots flying into secondary airports was negligible.

The experience from participating First Officers ranged between 1 and 8 years (mean 6.58; $\sigma=$ 4.40) and Captains from 1 to 20 years (mean 7.37; $\sigma=5.87$ ) years of experience as pilots. The average years of the First Officers includes the experience which Captains reported before upgrading. 
Figure 3 - Mean pilots experience in years

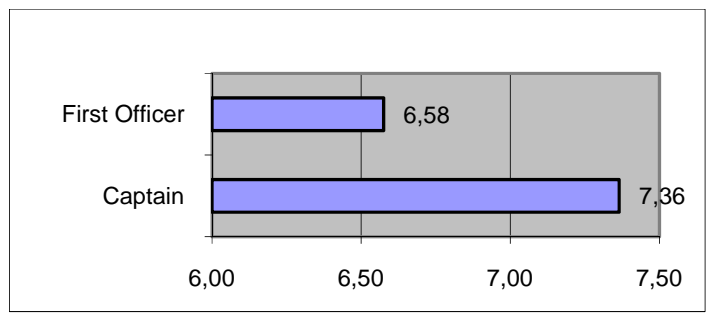

\section{Pilots' I nformation Requirements}

In this section, the results concerning pilots' information requirements will be shown as a function of 'delays avoidable' as reported by pilots. Table 5 shows the mean values that received high ratings of the five proposed turn-round situations:

Figure 4 - Mean rating 'delays avoidable'

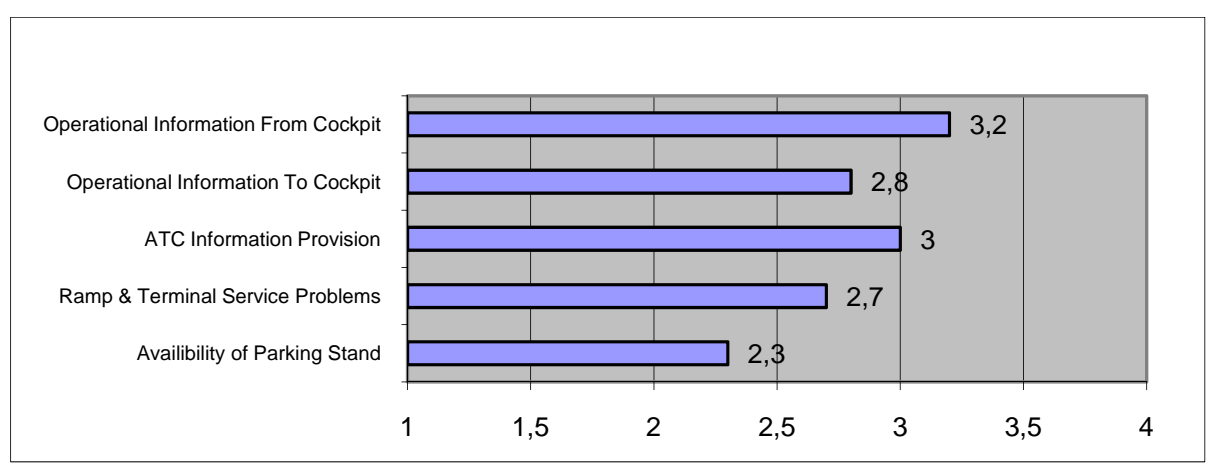

Pilots assigned highest ratings to the statement 'need to take information into account which was proposed by pilots', where pilots see least options to avoid delays through 'timely notification of problems with parking stand assignment'. However, the initial hypothesis that 'reliable provision of operational information to the pilots is correlated with 'delays avoidable'did not show statistical significance.

Pilots were asked to report events they experienced; however, most of the pilots used the proposed situations in the questionnaire which were verified as 'critical' during focus group meetings. Table 4 shows reported frequency of the five proposed turn-round situations of all participating pilots and reported turn-round events as frequency in percentage terms. 
Table 4: Turn-round events as reported by pilots

\begin{tabular}{|c|c|c|}
\hline Turn-Round Problem & $\begin{array}{l}\text { Reported Situation } \\
\text { Frequency in } \%\end{array}$ & $\begin{array}{l}\text { Reported Event } \\
\text { Frequency in \% }\end{array}$ \\
\hline SITUATION I: Availability of Parking Stand & 95,1 & 95,1 \\
\hline SITUATION II: Baggage Loading/ Unloading & 100 & 47,1 \\
\hline SITUATION II Ramp Transfer Bus (Passenger or Crew) & 100 & 11,8 \\
\hline SITUATION II: Catering & 100 & 1 \\
\hline SITUATION II: Cleaning & 100 & 2,9 \\
\hline SITUATION II: Fueling & 100 & 4,9 \\
\hline SITUATION II: Check-In & 100 & 1 \\
\hline SITUATION II: Security & 100 & 2 \\
\hline SITUATION II: Boarding & 100 & 13,7 \\
\hline SITUATION II: Airport Facilities & 100 & 4,9 \\
\hline SITUATION II: Wheelchairboarding & 100 & 3,3 \\
\hline SITUATION II: UM Boarding & 100 & 0 \\
\hline SITUATION II: Special Loading (e.g. musical instrument) & 100 & 1 \\
\hline SITUATION II: VIP Boarding & 100 & 5,9 \\
\hline SITUATION II: Missing Flight Documents & 100 & 2 \\
\hline SITUATION III: ATC Request & 95,1 & 99 \\
\hline SITUATION IV: Aircraft Change & 95,1 & 63,1 \\
\hline SITUATION IV: Crew Duty Change (new duty roster) & 95,1 & 18,4 \\
\hline SITUATION IV: Crew Change (new crew member) & 95,1 & 1,9 \\
\hline SITUATION IV: Technical Repair & 95,1 & 7,8 \\
\hline SITUATION IV: Other & 95,1 & 3,9 \\
\hline SITUATION V: Crew Proposal: Connecting Passenger & 93,2 & 5,8 \\
\hline SITUATION V: Crew Proposal: Necessary A/C repair & 93,2 & 33 \\
\hline SITUATION V: Crew Proposal: Avoidance of A/C Change & 93,2 & 47,5 \\
\hline SITUATION V: Crew Other Proposal & 93,2 & 5,8 \\
\hline
\end{tabular}

\section{Effect of Process Delay on Departure Punctuality}

A significant correlation could be identified for turn-round processes which produced a delay in relation to the departure delay after turn-round as shown in percent of all reported delays. However, since values of both variables result from qualitative assessment of the situations, only subjective information can be deducted. The following figures show the proposed situations; late parking stand assignments (figure 5), ramp \& terminal service delivery (figure 
6), operational information sharing to cockpit (figure 7), and operational information sharing from cockpit (figure 8).

Figure 5 - Process \& departure delay for Figure 6 - Ramp \& terminal service delivery parking stand assignment

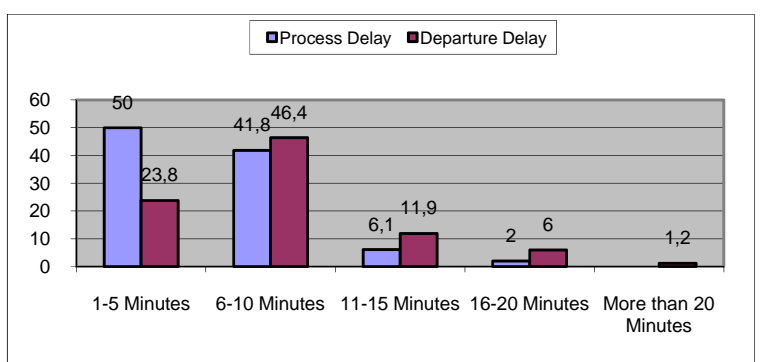

Note: Spearman's rho $=0.363, p=0.001$, two tailed test, $\mathrm{N}=84$

Figure 7 -Operational information to cockpit

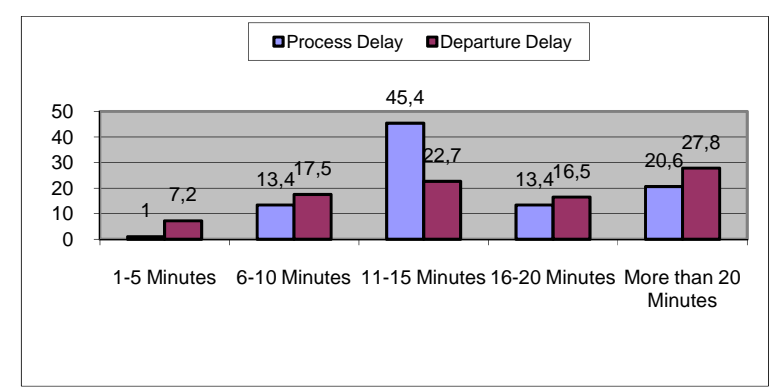

Note: Spearman's rho $=0.760, p=0.000$, two tailed test, $\mathrm{N}=97$

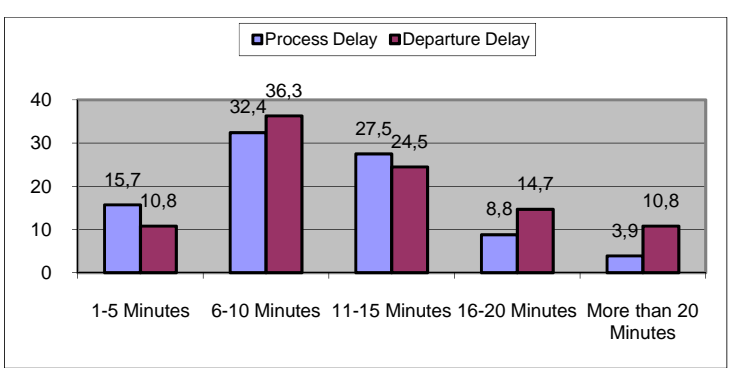

Note: Spearman's rho $=0.424, p=0.000$, two tailed test, $\mathrm{N}=102$

Figure 8 - Operational information from cockpit

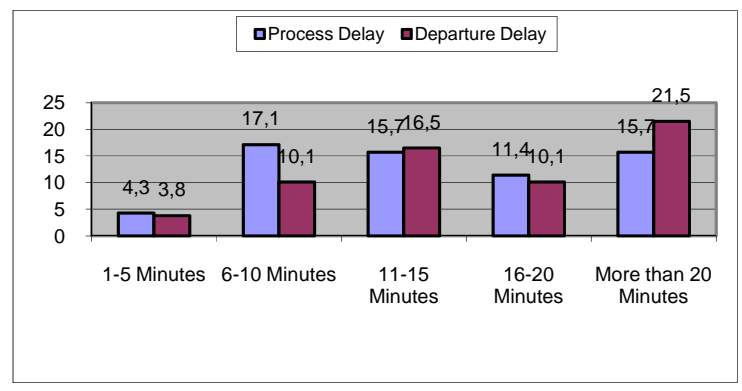

Note: Spearman's rho $=0.854, p=0.000$, two tailed test, $\mathrm{N}=79$

Even though it is not possible to infer that the turn-round process delay exclusively causes the overall departure delay, it entails a high risk of being responsible for the delay since also the amount of delay correlates significantly between process delay and departure delay. It can be argued that this result is based on a subjective assessment by pilots and is therefore not based on real turn-round data. However, in all situations pilots are always directly affected by the delay and physically present when the turn-round takes place. 


\section{Possible Cooperation Failure during Flight Operation}

Even though it could be argued that pilots would be unable to identify failure causes objectively, it is very likely for following reason: pilots have operational experience from a home base airport which they are familiar with. Since all participating pilots fly for airlines having a large network, pilots can easy compare turn-round services from other airports with their home base. This allows a unique way to compare service provision of various airports. Figure 9 compares the mean ratings for aims, resources, and abilities as causes of possible information sharing failure by pilots.

Figure 9 - Possible information sharing failure causes

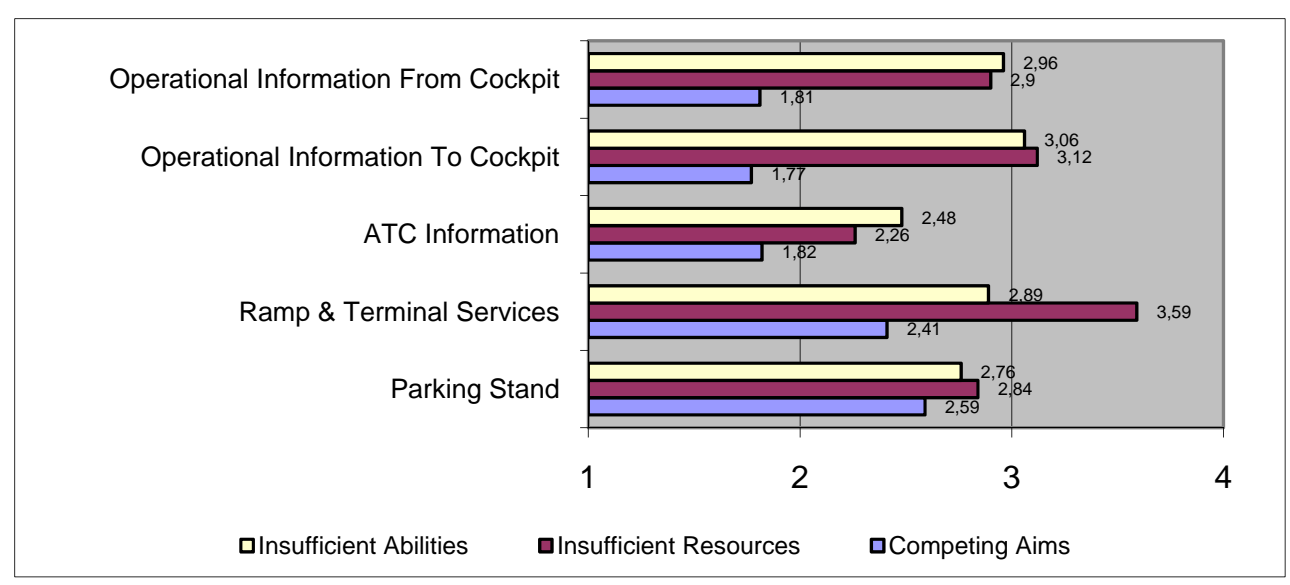

During all situations except ATC information, insufficient resources were seen as being primarily responsible for turn-round delays. Ramp and terminal services in particular, appear to be particularly affected by the problem of insufficient resources. The only non-cooperative situation from pilots' perspective, analogous to Ferber's cooperation model, is the pilots mean rating for the assignment of parking stands.

Pilots were also asked to report about possible other reasons for process failures. Most frequently reported causes included the following in Figure 10. The first reason refers to a turn-round time which is too short: If this is the case, there is not sufficient time to compensate for any process delay. The second reason implies that important information may be hidden among the unimportant. The third reason is that there appears to be an inappropriate sharing 
of responsibility functions for decision making, and last reason refers to inappropriate communication facilities in order to address concerns during turn-rounds.

Figure 10 - Possible other reasons for problems with the turn-round process

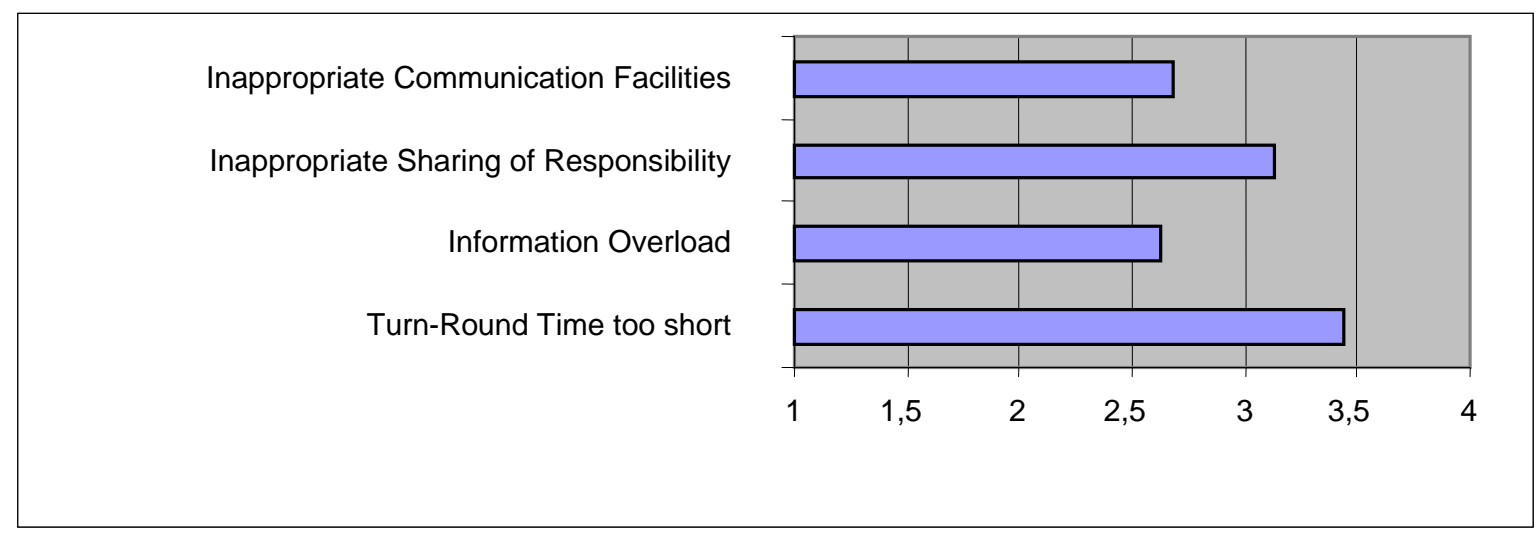

\section{DISCUSSION \& REVIEW PROCEDURE}

The most important result from the survey is captured by the apparent consensus that exists between pilots that information sharing is a root cause for process failures during flight operation. Furthermore, what was particularly noticeable from the survey was the frequency of these reported events. The survey also found that a strong relationship exists between on the one hand the delay from a service or information provision failure and on the other hand it's effect on the departure punctuality of the following flight for all contemplated situations. Additionally, in almost all reported events, departure delay was more significant after turnround as a result of information provision failure compared to delay caused by service provision failure. A possible explanation could be the so-called phenomenon of a bullwhip-effect where the network of service providers can oscillate in very large swings as each organization in the supply-chain (critical path of turn-round events) seeks to solve the problem from its own perspective and so raising the outcome of the problem (here the outcome is the departure delay after passing the critical path of ground handling services). This is a very common problem in the management of production lines where many partners are involved. However this has to be validated via additional information collection because the delay following a service/ information provision failure could also be caused by other not yet identified factors. 
No correlation could be observed between proposed information provision to cockpit and a consequent avoidance of ground handling service delay. This is because either pilots are not aware of the opportunity to avoid a potential problems through usage of the supplied information (e.g. arranging alternative ways of ground handling), or there exists a real lack of resources, capabilities, aims, or other not yet identified reasons responsible for service delays.

Surprising high results were reported from delays caused by failures to provide operational information from and to the cockpit. This finding provides some indication as to the cockpit's perspective on the problem and how airlines or ground handlers are managing the operational processes. Contemplated operational problems included e.g. changes of equipment, parking position, or crew, re-booking or direct transfer of connecting passengers. Operational planning for such events requires pre-planning with other airport partners and is necessary in order not to maintain the integrity of pre-planned departure times.

Overall, this study is the first attempt to understand the cooperation building process during Airport Collaborative Decision Making. It could be identified that the distributed CDM environment showed unique interaction characteristics with multiple individual operators' goals settings, while the airline pilot's perspective revealed being useful for the analysis of possible operator's thoughts.

De Ferber's interaction model identified potential non-cooperative behaviour during flight operation. The results from the questionnaire should now be used to evaluate a re-design of the currently used CDM approach. New design elements should recognize the problems of human information interactions during flight operation, as well as operators' behavioural characteristics assessing the complexity of each individual flight operation situation.

\section{ACKNOWLEDGEMENTS}

The authors would like to thank all participating pilots from Air Berlin, Air France, Austrian, Easy Jet, Lufthansa CityLine, and Transavia for their collaboration in this study.

The authors would also like to thank EUROCONTROL Experimental Centre and FRAPORT Foundation 'Erich Becker' for their financial support. 


\section{REFERENCES}

- Carlier, X. \& Hoc, J.M. (2002). Role of Common Frame of Reference in Cognitive Cooperation: Sharing Tasks between Agents in Air Traffic Control. Cognition, Technology \& Work 4, 37-47, Springer-Verlag London.

- De Terssac, G. \& Chabaud, D. (1990). Réferentiel opératif commun et fiabilité. In J.Leplat \& G.de Terssac (Eds.), Les facteurs humains de la fiabilité dans les systems complexes (pp. 110-139), Toulouse.

- Ferber, J. (1995). Multi-Agent Sytems, Addison-Wesley, Muenchen, Germany.

- Groppe, M. \& Bui, M. (2008). "Study of Cockpit's Perspective on Human-Human Interactions to Guide Collaborative Decision Making Design in Air Traffic Management," $A C H I$, pp. 107-113, IEEE Proceedings of First International Conference on Advances in Computer-Human Interaction.

- Hoc, J.M. (1988). Cognitive psychology of planning, Academic Press, London, UK.

- Hoc, J.M. (2001). Towards a cognitive approach to human-machine cooperation in dynamic situations, Human-Computer Studies 54, 509-540.

- Hoc, J.M. \& Lemoine, M.P. (1998). Cognitive evaluation of human-human and humanmachine cooperation modes in air traffic control. International Journal of Aviation Psychology 8.1-32.

- Hoc, J.M. (2000). From human-human interaction to human-machine cooperation. Ergonomics, 43, 833-843.

- Jennings, N.R.; Norman, T.J. \& Panzarasa, P. (2001). Formalizing Collaborative Decision Making and practical reasoning in Multi-Agent Systems, Journal of Logics \& Communication 12 (1) 55-117.

- Keisler, S. \& Cummings, J.N. (2002). What Do We Know About Proximity in Work Groups?, In P. Hinds and S.Keisler (Eds). Distributed Work, Cambridge, MA, MIT Press.

- Lee, P.U. (2005). Understanding Human-Human Collaboration to Guide HumanComputer Interaction Design in Air Traffic Control, NASA Ames Research Center, CA, USA.

- Piaget, J. (1965). Études sociologiques, Genève, Switzerland.

- Salas, E.; Prince, C.; Baker, D. \& Shrestha, L. (1995). Situation awareness in team performance: implications for measurement and training, Human Factors, 37, 123-136. 
- Schmidt, K. (1994). Cooperative work and its articulation: requirements for computer support. Le Travail Humain, 57, 345-366.

- Terveen, L.G. (1995). An overview of human-computer collaboration, Knowledge-Based Systems, 8 (2-3), 67-81.

- Warner, N.W.; Vanderwalker, S. \& Verma, N. (2002). State of the Art Review on HumanHuman Collaboration Research: An Integrated, Multidisciplinary Perspective, Naval Research Centre, Arlington VA.

- Warner, N.W. \& Wroblewski, E. (2003). The Cognitive Process Used in Team Collaboration During Asynchronous, Distributed Decision Making, Command and Control Research and Technology Symposium, June 15-17, 2004, San Diego CA. 